\title{
A GRAMÁTICA DAS CRIANCINHAS: UM PROJETO INOVADOR DA EDUCADORA PORTUGUESA VIRGÍNIA GERSÃO ${ }^{1}$
}

\author{
Sónia Coelho \\ Susana Fontes ${ }^{3}$
}

\section{RESUMO}

No presente artigo, temos como objetivo dar a conhecer e analisar A gramática das criancinhas (1921), uma obra redigida pela então professora portuguesa Virgínia Faria Gersão (1896-1974), para o ensino da gramática nos primeiros anos escolares. A abordagem bastante original que a autora confere ao texto faz desta obra um documento de elevado interesse para a história do ensino gramatical em Portugal. Nesta investigação, é nosso objetivo levar a cabo uma análise das estratégias usadas pela autora na explicação dos conteúdos gramaticais, criadas com o propósito de facilitar a aprendizagem dos alunos. O nosso estudo permite-nos concluir que o seu pensamento pedagógico faz eco das principais correntes da época, revelando ainda pertinência na atualidade.

${ }^{1}$ Este trabalho é financiado por fundos nacionais através da Fundação para a Ciência e a Tecnologia (FCT), no âmbito do Centro de Estudos em Letras, com a referência UID/LIN/o0707/2019, Portugal.

2 Universidade de Trás-os-Montes e Alto Douro (Utad), Vila Real, Portugal.

3 Universidade de Trás-os-Montes e Alto Douro (Utad), Vila Real, Portugal. 
Palavras-chave: Virgínia Faria Gersão, A gramática das criancinhas, ensino primário, língua materna, estratégias didáticas, ensino gramatical.

\title{
A GRAMÁTICA DAS CRIANCINHAS: UN PROYECTO INNOVADOR DE LA EDUCADORA PORTUGUESA VIRGÍNIA GERSÃO
}

\section{RESUMEN}

En el presente artículo, tenemos como objetivo dar a conocer y analizar la obra A gramática das criancinhas (1921), redactada por la entonces profesora portuguesa Virgínia Faria Gersão (1896-1974), para la enseñanza de la gramática en los primeros años escolares. El enfoque bastante original que la autora confiere al texto hace de su obra un documento de alto interés para la historia de la enseñanza gramatical en Portugal. En esta investigación, es nuestro objetivo llevar a cabo un análisis de las estrategias usadas por la autora en la explicación de los contenidos gramaticales, creados con el propósito de facilitar el aprendizaje de los alumnos. Nuestro estudio nos permite concluir que su pensamiento pedagógico hace eco de las principales corrientes de la época, revelando aún pertinencia en la actualidad.

Palabras clave: Virgínia Faria Gersão, A gramática das criancinhas, enseñanza primaria, lengua materna, estrategias didácticas, enseñanza gramatical.

\section{A GRAMÁTICA DAS CRIANCINHAS: AN INNOVATIVE PROJECT OF THE EDUCATOR VIRGÍNIA GERSÃO}

\begin{abstract}
In this paper, we aim to present and analyze the work A gramática das criancinhas (1921), written by the then Portuguese teacher Virgínia Faria Gersão (1896-1974) for the teaching of grammar during the first years of school. The very original approach that the author confers to her text renders this work a document of high interest for the history of grammatical teaching in Portugal. In this investigation, it is our objective to carry out an analysis of the strategies used by the author in the explanation of the grammatical contents, created with the purpose of facilitating the students' learning. Our study allows us to conclude that the author's pedagogical thinking echoes the main trends of the time, still revealing to be pertinent nowadays.

Keywords: Virgínia Faria Gersão, A gramática das criancinhas, primary education, mother tongue, didactic strategies, grammar teaching.
\end{abstract}




\section{A GRAMÁTICA DAS CRIANCINHAS: UN PROJET NOVATEUR DE L'ÉDUCATRICE PORTUGAISE VIRGÍNIA GERSÃO}

\section{RÉSUMÉ}

Dans le présent article, nous souhaitons présenter et analyser l'œuvre A gramática das criancinhas (1921), rédigée par Virgínia Faria Gersão (1896-1974), une enseignante portugaise de l'époque, destinée à l'enseignement de la grammaire des premières années scolaires. L'auteure fait une approche très originale du texte ce qui rende son ouvrage un document d'un grand intérêt pour l'histoire de l'enseignement de la grammaire au Portugal. Dans cette recherche, notre objectif est d'analyser les stratégies utilisées par l'auteure pour expliquer les contenus grammaticaux, dans le but de faciliter l'apprentissage des élèves. Notre étude nous permet de conclure que sa réflexion pédagogique fait écho des principaux courants de l'époque et continue encore à être pertinent dans l'actualité.

Mots-clés: Virgínia Faria Gersão, A gramática das criancinhas, enseignement primaire, langue maternelle, stratégies didactiques, enseignement de la grammaire. 


\section{INTRODUÇÃO}

O final do século XIX e o início do século XX caracterizam-se por um fervilhar de ideias inovadoras que levaram ao surgimento de um novo paradigma na educação, a Educação Nova. Personalidades notáveis como Maria Montessori (1870-1952), Édouard Claparéde (1873-1940) ou Adolphe Ferrière (1879-1960) dão importantes contributos para esta mudança, refletindo acerca dos novos princípios e métodos que deveriam nortear a educação. Contestando o modelo tradicional de ensino, caracterizado por uma desvalorização do período da infância, estes pensadores, com base na filosofia já postulada por Rousseau de que a criança deve ser encarada enquanto tal e não como um adulto em miniatura, preconizam que a escola passe a centrar-se nela e nos seus interesses. Neste sentido, este movimento de renovação pedagógica orienta-se por um conjunto de princípios que passam por uma educação integral, uma escola ativa, a autodisciplina, o respeito pela individualidade do aluno, entre outros, de forma a dar resposta às principais preocupações que envolviam o contexto pedagógico.

Em Portugal, as experiências encetadas por estes teóricos e o seu ideário pedagógico tiveram considerável impacto e motivaram pedagogos como António Sérgio (1883-1969), Luísa Sérgio (1880-1960) e Álvaro Viana de Lemos (18811972) a envolverem-se ativamente na renovação das práticas pedagógicas, condenando o ensino abstrato, teórico, em que o professor representava uma autoridade máxima e que não podia ser questionada.

É neste contexto de renovação que situamos a vida e a prática pedagógica de Virgínia Faria de Gersão4 (1896-1974), uma educadora portuguesa que se destacou nos inícios do século $\mathrm{XX}$, por defender um ideário que colocava a criança no centro do ato educativo, deixando-o plasmado nos seus escritos.

Esta autora estudou na antiga Escola Normal de Coimbra e licenciou-se

\footnotetext{
4 Acerca da vida e obra da autora, veja-se, entre outras fontes, Castelo (2003) e Souza (2005).
} 
em Filologia Românica pela Universidade de Coimbra.5 Exerceu primeiramente a docência em 1927 enquanto professora agregada na Escola Normal Primária de Lisboa, onde lecionou Português e depois enquanto professora efetiva no Liceu Infanta D. Maria em Coimbra, tendo lecionado Português e Francês.

Num contexto bastante adverso à mulher, Virgínia Gersão foi convidada para desempenhar o cargo de deputada à Assembleia Nacional entre os anos de 1945 e 1949 (BRAGA, 2011), juntamente com a médica Maria Luísa Van Zeller (1906-1983), integrando a comissão da Educação Nacional, Cultura Popular e Interesses Espirituais e Morais. As suas intervenções parlamentares debruçaram-se sobre assuntos como a tuberculose, o ensino técnico profissional, a reforma liceal e o ensino particular.

No âmbito da educação, publicou textos em periódicos da época, em que discutiu questões relativas ao estado do ensino em Portugal, defendendo, por exemplo, a necessidade da instrução da mulher com vista à sua inserção na vida ativa $^{6}$ (PINTASSILGO; SERRA, 2009). Escreveu, ainda, obras de cunho literário, designadamente peças de teatro infantil, e também obras vocacionadas para o ensino, como a Geometria das criancinhas (1933) e A gramática das criancinhas (1921).

Esta última obra constitui-se como um importante documento para a história do ensino em Portugal, revelando o ideário da autora e encontrando-se em consonância com as práticas mais avançadas da época. Nela, Virgínia Gersão adotou um estilo inovador, colocando a criança no centro da aprendizagem e promovendo um ensino ativo e motivador.

O carácter pioneiro de A gramática das criancinhas motivou o presente estudo, através do qual pretendemos dar a conhecer esta obra, evidenciando o

\footnotetext{
5 Vaquinhas (2014, p. 113) dá-nos conta de que Virgínia Gersão se encontrava inscrita na Faculdade de Letras da Universidade de Coimbra, no ano letivo de 1915-1916.

${ }^{6}$ Nesta época, em Portugal, o acesso da mulher à instrução ainda era limitado, o que motivou Virgínia Gersão (1913, p. 3), com apenas 17 anos, a escrever um texto em que defendia a necessidade de a mulher aceder à educação: "Nem todas as mulheres se destinariam a doutoras, mas a todas se poderiam ministrar conhecimentos geraes e profissionaes que só esse bem reverteriam para a sua vida prática".
} 
seu interesse pedagógico e a atualidade das suas propostas. Neste sentido, dividimos o presente trabalho em três partes. Num primeiro momento, analisamos as ideias que marcaram o pensamento da autora ao nível da educação e que se refletiram na redação desta obra. Num segundo momento, por forma a perceber-se o contexto em que a gramática foi redigida, debruçamonos sobre as orientações programáticas em vigor, particularmente sobre a componente gramatical presente no Programa de Português para o Ensino Primário Geral. Finalmente, na última parte, destaca-se a abordagem original que a autora confere ao tratamento dos conteúdos gramaticais, demonstrando o seu pendor didático e focado na criança, fazendo desta obra uma gramática inovadora.

\section{A EDUCAÇÃO AOS OLHOS DE VIRGÍNIA FARIA GERSÃO}

Para melhor compreendermos as opções metodológicas da autora na redação de A gramática das criancinhas, importa atentar nas suas ideias acerca do estado da educação em Portugal, tomando como fonte os seus escritos em periódicos da época, assim como os discursos que proferiu enquanto deputada na Assembleia Nacional.

No artigo intitulado "A distracção das crianças", publicado na revista $O s$ nossos filhos, Virgínia Gersão reflete de uma forma muito sistemática sobre um conjunto de causas que poderiam estar na base da falta de atenção que afetava as crianças, elencando doze motivos, entre os quais encontramos, por exemplo, o pouco interesse que os alunos demonstravam por algumas aulas, devido à dificuldade em acompanhar determinadas matérias, a inadequação dos programas, o automatismo e a velocidade que se exigiam à criança e a desmotivação em que a mesma caía devido ao elevado nível de exigência (GERSÃO, 1945, p. 9). 
Dois anos mais tarde, num dos discursos proferidos no parlamento, de entre os vários fatores anteriormente enunciados, Gersão elege a falta de adaptação dos programas como principal motivo para a distração dos alunos, apresentando a seguinte justificação: "Não os acho adequados à idade dos alunos nem vejo que se parta, como o exige rigorosamente o primeiro princípio da verdadeira pedagogia, do mais simples para o mais complexo, do geral para o especial" (GERSÃO, 1947, p. 447). Das palavras da educadora, fica evidente a sua perspetiva crítica em relação às debilidades que caracterizavam os programas de ensino em vigor, sobretudo porque se exigia demasiado dos alunos, não atendendo às especificidades da sua faixa etária: "O vício actual, logo no começo dos estudos, é encher o cérebro dos alunos de coisas que pouco valem; e, a propósito de os habituarmos a raciocinar depressa, nem vemos que os tornamos quase autómatos" (GERSÃO, 1947, p. 447).

Neste sentido, propõe que, nos diferentes graus de ensino, se progrida gradualmente, excluindo o que for desnecessário e desajustado ao ano em causa. Esta inadequação dos programas culminava, em seu entender, numa excessiva sobrecarga dos alunos, que passavam grande parte do seu tempo a memorizar conhecimentos, muitas vezes inúteis, e acabavam por criar uma aversão ao estudo:

\begin{abstract}
Mas que a essa criança, em pleno desenvolvimento físico, cheia nas primeiras idades da necessidade de brinca e colar, se negue o que é, afinal, a sua vida e se permita que tenha todas as noites os olhitos a fechar-se com sono e uma série infinita de problemas por fazer, a redacção por passar, regras frias de gramática para meter na cabeça, porque a História e a Corografia lhe levaram o pouco tempo livre durante o dia, é o que se chama, penso eu, um crime! (GERSÃO, 1947, p. 448).
\end{abstract}

Em seu entender, a criança passava demasiado tempo na escola, carecendo de tempo livre para si própria, sendo educada como se de um adulto se tratasse. Como a educadora defende num artigo dedicado explicitamente à necessidade de a criança brincar, devem respeitar-se as leis da infância, para 
que cada etapa possa ser vivida na sua plenitude e atendendo às suas especificidades, tal como defendera Maria Montessori.

A desconsideração das necessidades da criança tinha como consequência "uma falta de atenção crescente, que se torna, dia a dia, verdadeiramente aflitiva; um desinteresse, quase geral, que domina turmas inteiras” (GERSÃO, 1947, p. 447).

Refletindo sobre o desinteresse generalizado dos alunos, a autora, para além de apontar os programas como uma das suas causas, crítica ainda o número excessivo de alunos por turma, que impossibilitava um trabalho mais produtivo e benéfico. Em seu entender, o professor tinha também um papel determinante na escolha da metodologia mais adequada e motivadora, para que as suas aulas se tornassem atrativas e conduzissem à aprendizagem por parte dos alunos:

\footnotetext{
Nenhuma reforma triunfa sem o concurso de duas condições fundamentais: a primeira é a rigorosa escolha do pessoal docente, capaz de fazer da sua carreira um sacerdócio e não só um ganha-pão; a segunda reside essencialmente na organização e adaptação dos programas, na amenização da parte teórica pela introdução de práticas acertadas (GERSÃO, 1947, p. 447).
}

Pelo seu discurso, percebe-se que a organização educativa e as práticas pedagógicas se encontravam limitadas pelo peso excessivo que tinham no ensino a demasiada teorização, a excessiva memorização e a passividade que a "escola tradicional” promovia nos alunos, ignorando o carácter ativo da criança que tanto se defendia na época, tendo por base os princípios da Educação Nova. Como refere Hameline (2010, p. 24), a respeito do pensamento de Claparède,

a escola deve ser ativa, laboratório e não auditório. O trabalho não pode, em hipótese alguma, ser insuportável. A escola constitui um meio social válido por si só e preparatório para as realidades da vida adulta. Nela, o pedagogo é, acima de tudo, um "estimulador do interesse". 
Como se pode comprovar, as questões abordadas por Virgínia Gersão nos diferentes palcos em que atuou revelam-nos uma mulher que não se limitava a ensinar, mas pensava o ensino e preocupou-se em apresentar propostas ajustadas com os movimentos mais inovadores da época.

\section{ORIENTAÇÕES PROGRAMÁTICAS PARA A APRENDIZAGEM DA GRAMÁTICA}

Os "Programas do Ensino Primário Geral" que vigoravam na época da redação de A gramática das criancinhas foram publicados em 1919, constituindo-se como o documento oficial e norteador para o ensino primário geral, contendo os conteúdos programáticos para as diferentes disciplinas que compunham o currículo e ainda um conjunto de instruções pedagógicas por forma a orientar a ação do professor.

$\mathrm{Na}$ época, o ensino inicial da língua materna tinha como objetivo principal facultar ferramentas ao aluno de modo a que este ficasse preparado para a vida ativa. Neste sentido, as próprias "Instruções Pedagógicas" para o ensino da língua e literatura portuguesa do curso normal indicavam ao futuro professor "[...] que o ensino da língua materna na escola primária tem por fim levar o educando a exprimir as suas ideas com a maior correcção, clareza e precisão possíveis, quer falando, quer escrevendo" (Decreto n. ${ }^{0}$ 6: 203, I SérieN. 227, Diário do Governo, 7 de novembro de 1919, p. 2318).

Por forma a cumprir este objetivo, uma das componentes fundamentais do programa de Português era a gramática, que devia ser lecionada de uma forma mais aproximada à realidade dos alunos, de modo a que pudessem verificar a sua aplicabilidade prática, visível, por exemplo, na capacidade de expressão dos educandos, pois "não se deve esquecer que a escola primária não pretende formar literatos, mas sim habilitar os seus alunos, na grande maioria futuros operários, a exprimirem os seus pensamentos de modo conveniente" 
(Decreto n. ${ }^{\circ}$ 6: 203, I Série-N. 227, Diário do Governo, 7 de novembro de 1919, p. 2318).

Neste sentido, entendia-se que o ensino gramatical devia abandonar o pendor abstrato e rígido que habitualmente o caracterizava e que tanto repudiava aos alunos.

No programa de Português, os conteúdos gramaticais surgiam apenas na $3 .^{\text {a }}$ classe, por se considerar que nesta fase era impossível progredir na disciplina sem que o aluno soubesse alguns conteúdos gramaticais, tais como as partes do discurso, os diferentes elementos da oração, as noções de género e número. Seria impensável, por exemplo, pontuar corretamente um texto sem um conhecimento prático da oração e do período.

Seguidamente, transcrevem-se os excertos relativos aos conteúdos gramaticais apresentados no referido Programa de Português (Decreto n. ${ }^{\circ}$ 6: 203, I Série-N. 227, Diário do Governo, 7 de novembro de 1919, p. 2232), no Quadro 1:

Quadro 1: Conteúdos gramaticais que figuram no Programa de Português (1919).

\begin{tabular}{|l|l|}
\hline CLASSE & CONTEÚDOS GRAMATICAIS NO PROGRAMA DE PORTUGUÊS (1919) \\
\hline $3 \cdot{ }^{\text {a }}$ classe & $\begin{array}{l}\text { "Conhecimento prático das principais partes do discurso, de modo que os alunos } \\
\text { distingam o substantivo do adjectivo e do verbo, o singular do plural, o masculino } \\
\text { do feminino. Conjugação dos verbos auxiliares e regulares". }\end{array}$ \\
\hline $4 \cdot{ }^{\text {a }}$ classe & $\begin{array}{l}\text { "Elementos de gramática por meio de exercícios práticos (partes variáveis e } \\
\text { invariáveis do discurso, conjugação dos verbos regulares e irregulares, elementos } \\
\text { da oração, distinção no período da oração principal)". }\end{array}$ \\
\hline $5 \cdot{ }^{\text {a classe }}$ & $\begin{array}{l}\text { "Recordação e esquematização das noções de gramática já aprendidas. Fáceis } \\
\text { exercícios sôbre sinónimos e antónimos e famílias de palavras". }\end{array}$ \\
\hline
\end{tabular}

Fonte: Diário do Governo (decreto n. ${ }^{\circ}$ 6: 203, I Série-N. 227, 7 de novembro de 1919, p. 2232).

É interessante notar que na enumeração dos conteúdos gramaticais surjam referências ao modo como o professor deve abordar estas matérias, sendo recomendada a utilização dos exercícios para facilitar o processo de 
aprendizagem. Esta ideia é defendida por Virgínia Gersão (1932, p. XIII), que, socorrendo-se de Fenélon, afirma que, neste nível de ensino gramatical, o princípio deve ser "Peu de règles, beaucoup d'exercices"7, o que seria uma forma de evitar a desmotivação e o enfado frequentemente associados ao ensino gramatical. Na introdução ao próprio programa de Português, alertava-se para esta situação:

\begin{abstract}
O comum horror pela gramática nas escolas primárias não é mais que uma reacção natural contra um excesso de ensino pedantesco, árido e desproporcionado à inteligência dos rapazes. E sendo êste horror um excesso, não pode todavia razoávelmente negar-se que um pouco de ordem nos conhecimentos, um certo esquema formal sempre que seja acompanhado duma representação concreta aumenta a clareza das ideas e facilita a sua fixação" (Decreto n. ${ }^{0}$ 6: 203, I Série-N. 227, Diário do Governo, 7 de novembro de 1919, p. 2231-2232).
\end{abstract}

É a consciência de que o ensino da gramática precisava de sofrer uma alteração, deixando de ser apenas um manual que a criança tinha de memorizar e tornando-a atrativa quer para o aluno quer para o professor, que leva Virgínia Gersão a construir uma gramática inovadora, com uma clara orientação didática. As suas palavras são bem elucidativas deste propósito: "O que eu quero, ou antes, o que eu queria, era que o professor não olhasse a Gramática com enfado, que a tornasse atraente aos olhos dos seus alunos, que lhe desse o aspecto irisado de beleza, e a não impusesse com a rigidez fria dum artigo do Código Penal” (GERSÃO, 1932, p. XI-XII).

Uma forma de motivar os alunos para o estudo da gramática era colocálos em contacto com textos do seu interesse e que espelhassem a sua realidade e as suas vivências. Tal como se defende atualmente, a gramática não deve ser abordada per se, em exercícios descontextualizados, mas deve partir de um texto, de forma a que o aluno veja aplicadas as regras gramaticais e possa desenvolver competências linguísticas, adotando uma postura reflexiva sobre os

\footnotetext{
7 Tradução nossa: [Poucas regras, muitos exercícios].
} 
usos da língua. As orientações que constavam no programa de Português apontam precisamente para essa prática:

O bom mestre fará, pois, tirar da leitura, da conversação, da correcção dos trabalhos, a regra gramatical, suscitando com arte casos dos quais pretenda derivar o preceito lingùístico. E dêste expediente se servirá com parcimónia, sem que o interêsse acessório ultrapasse o principal" (Decreto n. ${ }^{\circ}$ 6: 203, I Série-N. 227, Diário do Governo, 7 de novembro de 1919, p. 2231).

Esta ideia é corroborada por Virgínia Gersão (1932, p. XV), que, a este respeito, afirma: "Na maior parte dos exemplos que cito no meu livro, as regras são tiradas de conversas: assim as crianças vêem melhor a importância dos estudos de Gramática”.

\section{A GRAMÁTICA DAS CRIANCINHAS (1921): PROPOSTAS DE VIRGÍNIA FARIA GERSÃO PARA O ENSINO DA GRAMÁTICA}

A gramática das criancinhas foi publicada, pela primeira vez, em 1921, tendo sido dedicada ao sobrinho da autora Carlos Augusto Gersão Ventura (1916-1992). ${ }^{8}$ Esta obra foi o resultado da dissertação de Virgínia Gersão para o exame de Estado do Curso de Habilitação para o Magistério Normal Primário e contou com uma segunda edição em 1932. Esta gramática foi ainda adaptada e publicada, ao longo de quatro anos, na revista Os Nossos Filhos em artigos intitulados “A Gramática no país das formigas”.

A gramática está estruturada em 26 lições, que funcionam como uma narrativa, na qual as personagens vão apresentando os conceitos gramaticais de uma forma natural e contextualizada, sendo a sua sistematização feita no final.

\footnotetext{
8 Este sobrinho de Virgínia Gersão foi professor da Escola Secundária Avelar Brotero, em Coimbra.
} 
A narrativa desenrola-se num país habitado por formigas, onde encontramos personagens como a Joaquinita, o Joaquim, a formiga-mestra, entre outras. Era intenção da autora que a obra fosse "[...] lida diante da Mãi como um livro de histórias, do Professor como um livro de lição" (GERSÃO, 1932, p. XIII).

Virgínia Gersão foi uma mulher muito interessada pelas questões do ensino, como vimos anteriormente, tendo uma clara vocação didática, visível particularmente no que respeita ao ensino da gramática, área que a própria assume merecer o seu 'melhor carinho'. No entanto, Gersão reconhece que os estudos gramaticais são muito exigentes e de difícil compreensão para os alunos, sendo necessário fazer sistemáticas repetições, "[...] variar os exemplos e quebrar-lhe, tanto quanto possível, a rigidez formal” (GERSÃO, 1948a, p. 194). Neste contexto, o professor tem um papel determinante na superação destes obstáculos: “Fazer-lhos vencer é o papel do professor” (GERSÃO, 1948a, p. 194).

É imbuída deste espírito que a autora redige $A$ gramática das criancinhas, na qual adota um estilo de abordagem ao ensino da gramática inovador e diferente dos moldes tradicionais, procurando explicar os conteúdos gramaticais com recurso à imaginação, à criatividade e ao lúdico. Como a própria reconhece, historicamente a gramática era ensinada de uma forma rígida e mecanizada, recorrendo-se muito à memorização, o que provocava $o$ desinteresse e antipatia por parte dos alunos.

Este método de ensino foi contestado na época por vários autores, nomeadamente por Ch. Charrier (1920, p. 214), que considerava que

\footnotetext{
les personnes âgées ont étudié la grammaire d'après la méthode dogmatique ou méthode d'autorité. Chaque élève avait "son" Noël et Chapsal, un manuel aux notions précises, mais combien sec et rebutant! Les maîtres, dévoués pourtant, ne faisaient rien pour en atténuer l'aridité'.
}

\footnotetext{
9 Tradução nossa: [as pessoas mais velhas estudaram a gramática de acordo com o método
} dogmático ou o método de autoridade. Cada aluno tinha o "seu" Noël e Chapsal, um manual 
Foi precisamente por este método que Gersão aprendeu a gramática, o que a levou a refletir sobre esta questão e a propor uma abordagem que atenuasse a tradicional aridez associada ao ensino dos conteúdos gramaticais, defendendo que "[...] o professor não olhasse a Gramática com enfado, que a tornasse atraente aos olhos dos seus alunos, que lhe desse o aspecto irisado de beleza, e a não impusesse com a rigidez fria dum artigo do Código Penal" (GERSÃO, 1932, p. XI-XII). É esta visão da gramática como algo atrativo e interessante que Gersão passa ao longo das páginas da sua obra, recorrendo várias vezes a expressões que a associam a estas características. Por exemplo, antes de iniciar o tratamento da classe dos nomes, a Formiga-mestre desperta a curiosidade da Joaquinita, criando uma expectativa elevada relativamente à aprendizagem, ao referir "Espera um bocadinho, porque eu hoje quero ensinar coisas muito bonitas" (GERSÃO, 1932, p. 5). Esta expectativa era constantemente renovada através de expressões motivadoras sobre o que iria ser estudado a posteriori, como se pode confirmar através da frase que se segue: “Depois há coisas mais lindas a aprender!” (GERSÃO, 1932, p. 86).

Noutro momento, são as próprias crianças, motivadas pela descoberta e pela aprendizagem conseguidas, que exclamam “-A Gramática é muito bonita!" (GERSÃO, 1932, p. 25), evidenciando o entusiasmo que o estudo destas matérias lhes provocava, o que contrasta com a habitual monotonia associada ao ensino da gramática. Este entusiasmo deve-se também ao facto de as crianças perceberem a utilidade e a importância dos estudos gramaticais:

\footnotetext{
Estava-se para começar a lição quando entrou a Raínha, que vinha visitar a Formiga-mestra e ao mesmo tempo saber como é que ela conseguia fazer com que os seus súbditos andassem sempre a estudar Gramática com tanto ardor.

- É para virem a falar bem, porque a Gramática dá leis para tudo isso, senhora Raínha (GERSÃO, 1932, p. 14).
}

com noções precisas, mas quão seco e desencorajador! Os mestres, embora dedicados, não fizeram nada para aliviar a sua aridez]. 
Por outro lado, o método utilizado é igualmente responsável pelo entusiasmo dos alunos para a aprendizagem destes conteúdos. Na perspetiva da autora, tendo em conta o panorama do ensino em Portugal, era necessário encontrar um método que evitasse a passividade dos alunos, a demasiada teorização e memorização, pouco benéficas para o ensino, pois, "[...] em vez de abrirmos esses cérebros para a luz, embrutecemo-los com acumulações e velocidades, tiramos-lhe todo o interesse pelo saber, criamos a indiferença, o deixa-correr, a passividade” (GERSÃO, 1948a, p. 193).

Posto isto, na introdução à obra, a autora defende a adoção de um método em que os alunos participem ativamente na construção do conhecimento, através de um "[...] ensino racional, explicando a razão dos termos adoptados, e sugestivo, falando de coisas que os interessem mais, relacionadas com estas lições” (GERSÃO, 1932, p. XII).

Como tal, é seu entendimento que, à semelhança do que acontece com as ciências naturais, o ensino se faça através de exemplos, podendo assim o aluno observar, analisar e retirar conclusões, sem que isso implique um elevado esforço de memória. Estas eram também as diretrizes preconizadas pelo Governo e plasmadas no programa de Português (Decreto n. ${ }^{0}$ 6: 203, I Série-N. 227, Diário do Governo, 7 de novembro de 1919).

Ao longo da obra, é visível esta preocupação da autora, que introduz os conteúdos a partir de exemplos diversificados e relacionados com as vivências das personagens, e só posteriormente apresenta o conceito a que se refere, levando a que sejam os alunos a concluírem a regra através do diálogo, como se exemplifica seguidamente a propósito do estudo dos advérbios:

-Ah! É verdade! Feliz é um adjectivo uniforme, tem só uma forma para o masculino e feminino; o outro é biforme...

- E daí que conclues?

- Que para formar o avérbio de modo se junta ao adjectivo na forma feminina o sufixo mente, se é biforme; se é uniforme junta-se à única forma o mesmo sufixo (GERSÃO, 1932, p. 108). 
Desta forma, contrariamente ao que era praticado, a autora adota um método de cariz indutivo para o ensino da gramática, encontrando-se afinada com os pedagogos do seu tempo. Charrier, por exemplo, defende que se aplique aos estudos gramaticais o mesmo método das ciências naturais:

L'emploi de la méthode déductive, en grammaire, constitue un nonsens. Placer la règle avant l'exemple, c'est vraiment mettre la charrue devant les boeufs. Sans doute, la méthode déductive convient à quelques enseignements, à celui de la géométrie, par exemple, parce que, là, le professeur part de définitions ou de principes rigoureusement exacts, pour en déduire des corollaires ou des applications. Mais la grammaire, comme la morale, comme les sciences naturelles, est une science d'observation et nécessite l'emploi de la méthode inductive. C'est de l'étude des faits du langage, c'est-àdire des exemples du livre ou de ceux indiqués par le maitre, que doivent se dégager les définitions et les règles. Règles et définitions suivent les exemples, au lieu de les précéder ${ }^{10}$ (CHARRIER, 1920, p. 215).

Estas ideias são acolhidas em A gramática das criancinhas, pois, como referido, ao longo desta obra os alunos têm um papel ativo na aprendizagem, sendo destacadas as suas descobertas nos próprios títulos dados a algumas lições, como por exemplo, à 14. ${ }^{a}$ lição, "Mais descobertas dos dois amigos" (GERSÃO, 1932, p. 67), ou à 18. a lição, "Mais descobertas da Joaquinita" (GERSÃO, 1932, p. 90).

Ainda em consonância com este método, está o princípio de que o ensino da gramática deve partir de um texto, como defende Ferdinand Brunot (1909, p. 69), fonte direta de Gersão: “[...] tout l'enseignement de la langue doit

\footnotetext{
10 Tradução nossa: [o uso do método dedutivo, na gramática, constitui um absurdo. Colocar a regra antes do exemplo é realmente colocar o carro antes dos bois. Sem dúvida, o método dedutivo é adequado para alguns ensinamentos, como a geometria, por exemplo, porque aqui o professor parte de definições ou princípios rigorosamente exatos, para deduzir corolários ou aplicações. Mas a gramática, como a moral ou as ciências naturais, é uma ciência de observação e requer o uso do método indutivo. É a partir do estudo dos factos da linguagem, isto é, a partir dos exemplos do livro, ou daqueles indicados pelo mestre, que se devem identificar as definições e as regras. As regras e as definições seguem os exemplos, em vez de os preceder].
} 
se faire sur un texte, partout et toujours"11. O ensino da gramática a partir de textos ou diálogos do interesse dos alunos motiva-os para o estudo e incentivaos a refletir sobre a língua, compreendendo melhor a utilidade da gramática. Esta relação profícua entre o texto e o ensino gramatical também está presente em A gramática das criancinhas, quando a professora pede aos alunos para selecionarem um texto, que servirá de base para a abordagem gramatical: "Àmanhã haveis de trazer o vosso livrinho de leitura, para vermos nêle coisas muito engraçadas. Lêde lá a história que achardes mais bonita, que eu quero que ma saibais contar, e depois ensino coisas de gramática, lá aplicadas; assim isto é mais bonito, mais útil, e aborrece menos" (GERSÃO, 1932, p. 12-13).

Outro aspeto merecedor de destaque nesta gramática prende-se com as diferentes formas de sistematização dos conteúdos adotadas pela autora. Seguindo aquilo que habitualmente se fazia numa aula, também aqui se recorre ao quadro para sintetizar as matérias e consolidar os conteúdos, reproduzindose nas páginas da gramática os esquemas realizados no quadro pelas personagens. É o que acontece, por exemplo, na página 34, quando do estudo dos graus dos adjetivos:

E escreveu no quadro prêto, com a sua patinha trémula:

O superlativo relativo
pode ser $\left\{\begin{array}{l}\text { de superioridade (quando o primeiro } \\ \text { é superior ao segundo); } \\ \text { de inferioridade (quando o primeiro } \\ \text { é inferior ao segundo) (GERSÃO, 1932, p. 34). }\end{array}\right.$

O recurso a um livro de apontamentos surge também ao longo da gramática como forma de sistematizar a matéria. Criados pela Joaquinita, estes Apontamentos de gramática esquematizam os conteúdos, permitindo uma leitura acessível e facilitando o estudo, à semelhança do que acontece com o caderno diário do aluno, como se exemplifica seguidamente:

\footnotetext{
11 Tradução nossa: [todo o ensino da língua deve ser sempre feito a partir de um texto].
} 
Era um livro pequenino, muito engraçado, feito por ela, e que tinha escrito na capa: Apontamentos e Gramática. [...]

1. ${ }^{\mathrm{a}}$ LIÇÃO

O Português tem têr- $\left\{\begin{array}{l}\text { do latim (sobretudo) } \\ \text { do grego } \\ \text { do fenício } \\ \text { do germânico } \\ \text { do árabe } \\ \text { do hebraico, etc.; e há têrmos só pe- } \\ \text { ninsulares (GERSÃO, 1932, p. 9). }\end{array}\right.$

Outra forma de sistematização dos conteúdos bastante inovadora, interessante e atrativa, adotada em três momentos da gramática, é o recurso a um jornal, criado pela autora, intitulado Revista Científica - Semanário ilustrado de propaganda científica, no qual os intervenientes davam a conhecer as suas descobertas gramaticais (Fig. 1). Segue-se o exemplo usado para a consolidação do estudo dos numerais:

Figura 1 - Sistematização dos numerais.

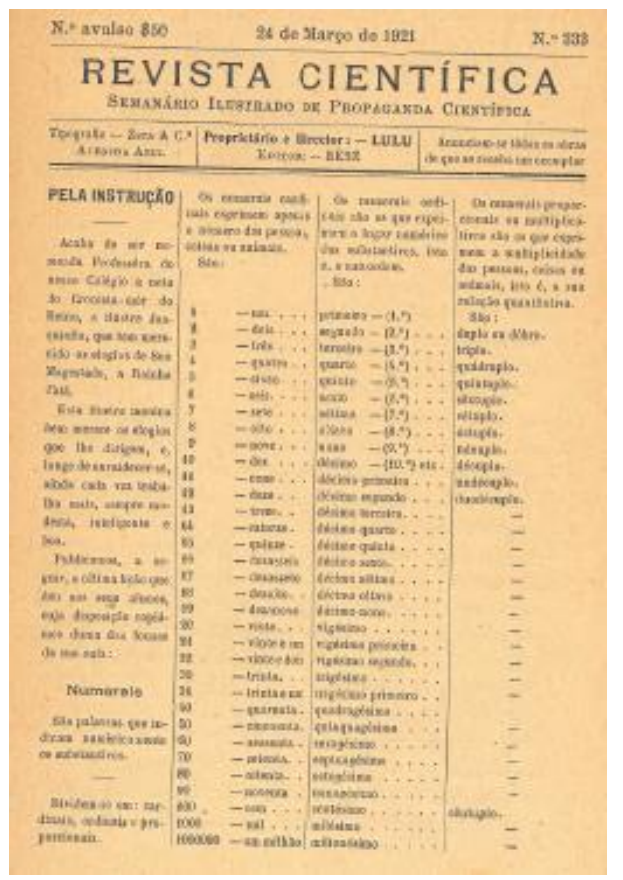

Fonte: GERSÃO (1932). 
Esta estratégia permite criar uma ligação entre o mundo escolar e o mundo real, conferindo-lhe um pendor mais prático, mostrando como é possível veicular de forma apelativa os conteúdos gramaticais.

As inovações metodológicas não se limitam à forma como a autora organiza os conteúdos, de forma a motivar os leitores para o estudo, estendemse também às estratégias a que recorre para os introduzir, que passam, por exemplo, pelo recurso ao jogo ou a bilhetes trocados entre as personagens, que nos remetem para a vida quotidiana. No caso concreto do conteúdo gramatical dos pronomes pessoais, Gersão socorre-se do "jôgo das bandeirinhas", no qual cada personagem representa um país e tem de fazer uso dos pronomes pessoais para se identificar: "Eu sou Portugal, tu a França e êle a Bélgica" (GERSÃO, 1932, p. 9). Esta estratégia que tem por base o lúdico está diretamente associada ao universo infantil, sendo muito eficaz para construir o conhecimento de uma forma mais estimulante e próxima das vivências dos alunos. Como a autora defende, a criança deve se respeitada enquanto tal, "educá-la como um adulto é um erro grave, apontado por todos os pedagogos. Nas primeiras idades só se pode ensinar brincando [...]" (GERSÃO, 1948b, p. 34).

Tendo por base esta linha de pensamento, em vários momentos da gramática, a autora incentiva as personagens a brincarem e termina as lições quando considera que os conteúdos apresentados já são suficientes para que as crianças os consigam apreender devidamente: "Mas eu já hoje ensinei muitas coisas e as minhas meninas confundem-se. Àmanhã torno a explicar tudo. Vão agora brincar, porque são horas do recreio. Brinquem muito, sejam muito amiguinhas, e não esfolem os joelhos na cabra-cega" (GERSÃO, 1932, p. 8).

Por outro lado, também há uma preocupação evidente na seleção dos conteúdos apresentados, evitando conteúdos demasiado complexos, que pudessem provocar o desânimo e a desmotivação dos alunos: "Eu poderia darvos muitas regras parecidas com estas, mas isso é demais para vós, meus filhos” (GERSÃO, 1932, p. 86).

Em todo este processo, o professor tem um papel determinante na 
escolha das melhores estratégias e metodologias, mas também na forma como se relaciona com os alunos. Na gramática, fica evidente que as conquistas das crianças constituem a verdadeira recompensa do professor, que se regozija com as suas aprendizagens: "Nisto a Formiga-mestra entrou na sala, e, a ver coisas tam lindas e tam bem feitas, ficou como que extasiada a olhar para o quadro, limpando as lágrimas que lhe caíam dos olhos” (GERSÃO, 1932, p. 63).

Na mesma linha de pensamento, verifica-se que Gersão se assume como contrária à prática da punição e do castigo físico, que atemorizava os alunos e inibia a própria aprendizagem. Nesta obra, não havia lugar à punição: “iMas, desde que a professôra tinha deixado os barretes de castigo e já não batia nem ralhava, as crianças corriam tôdas para a escola, porque ela até brincava nos recreios com as pequenitas!" (GERSÃO, 1932, p. 20).

Nesta época, o modelo do velho mestre-escola começava a ser questionado, debatendo-se a questão da disciplina escolar e propondo-se alterações que contrariassem a submissão total do aluno, a obediência cega e a severa punição e valorizassem a autodisciplina e a consciência clara do que era correto e adequado.

\section{CONSIDERAÇÕES FINAIS}

Virgínia Faria Gersão foi uma mulher de elevada cultura, que se destacou nos inícios do século XX em Portugal, desempenhando funções que eram de difícil acesso às mulheres, como é o caso do cargo de deputada à Assembleia Nacional. Neste e noutros contextos, teve um papel ativo na defesa da instrução pública, considerando a infância como um período crucial, cujas características deviam ser reconhecidas e respeitadas no processo de aprendizagem, perfilhando as ideias sobre a educação que grassavam na época.

A gramática das criancinhas, obra sobre a qual nos debruçámos, reflete claramente esta mudança de paradigma, colocando a criança no centro do 
processo de aprendizagem, através de uma abordagem completamente inovadora do ensino da gramática.

Aliando a aprendizagem ao lúdico e à imaginação, esta obra surge como uma tentativa de ultrapassar a dificuldade associada aos estudos gramaticais. $\mathrm{O}$ texto é pensado em função da aprendizagem efetuada nos primeiros anos escolares, por isso a autora recorre a diferentes estratégias que contribuem claramente para a motivação da criança, afastando-se do ensino tradicional e facilitando a aprendizagem da gramática. As suas propostas revelam uma nítida preocupação com a prática pedagógica, podendo, muitas delas, ser consideradas atuais.

Neste sentido, A gramática das criancinhas, obra ainda hoje injustamente desconhecida, constitui um importante e original contributo para o ensino da gramática nos inícios do século XX.

\section{REFERÊNCIAS}

BRAGA, Paulo Drummond. A educação em debate na Assembleia Nacional: o contributo das mulheres deputadas (1945-1957). E-Paper 1, 2011.

BRUNOT, Ferdinand. L'enseignement de la langue française. Ce qu'il est - Ce qu'il devrait être dans l'nseignement primaire. Paris: Librairie Armand Colin, 1909.

CASTELO, Cláudia. Gersão, Virgínia Faria. In: NÓVOA, António (Dir.).

Dicionário de educadores portugueses. Lisboa: Asa Editores, 2003. p. 625-626.

CHARRIER, Ch. Pédagogie vécue. Cours complet et pratique. Nouvelle édition, revue et corrigée. Paris: Librairie Classique Fernand Nathan, 1920.

DIREÇÃO GERAL DO ENSINO PRIMÁRIO E NORMAL. Decreto n. ${ }^{\circ}$ 6: 203, I Série-N. 227, Diário do Governo, 7 de novembro de 1919.

GERSÃO, Virgínia Faria. A distracção das crianças. Os nossos filhos, n. 43, p. 9, 1945 . 
GERSÃO, Virgínia Faria. A geometria das criancinhas. Coimbra: Livraria Gonçalves, 1933.

GERSÃO, Virgínia Faria. A gramática das criancinhas. Coimbra: Livraria Nogueira, 1921.

GERSÃO, Virgínia Faria. A gramática das criancinhas. Coimbra: Livraria Gonçalves, 1932.

GERSÃO, Virgínia Faria. A mulher e a educação. Educação feminina, n. 1, p. 3,1913 .

GERSÃO, Virgínia Faria. Sessão n. ${ }^{0}$ 128, em 27 de Janeiro. Diário das sessões, n. 128, p. 192-194, 28 jan. 1948a.

GERSÃO, Virgínia Faria. Sessão n. ${ }^{\circ}$ 161, em 10 de Dezembro. Diário das sessões, n. 161, p. 34, 11 dez. 1948 b.

GERSÃO, Virgínia Faria. Sessão n. ${ }^{0}$ 82, em 30 de Janeiro. Diário das sessões, n. 82, p. 444-448, 1 fev. 1947.

HAMELINE, Daniel. Edouard Claparède. Recife: MEC, Fundação Joaquim Nabuco, Editora Massangana, 2010.

PINTASSILGO, Joaquim; SERRA, Áurea Esteves. A educação feminina (1913), um projecto das "Normalistas de Lisboa". In: PINTASSILGO, Joaquim; SERRAZINA, Lurdes (Org.). A Escola Normal de Lisboa e a formação de professores: arquivo, história e memória. Lisboa: Edições Colibri, Centro de Investigação em Educação, 2009. p. 79-98.

SEABRA, Maria Judite. Liceu Infanta D. Maria, em Coimbra. In: NÓVOA, António; SANTA-CLARA, Ana Teresa (Coord.). "Liceus de Portugal"Histórias, arquivos, memórias. Porto: Edições Asa, 2003. p. 203-221.

SOUZA, Maria Reynolds de. Virgínia Faria Gersão. In: CASTRO, Zília Osório de; ESTEVES, João (Dir.). Dicionário no feminino (século XIX-XX). Porto: Livros Horizonte, 2005. p. 886-888.

VAQUINHAS, Irene. A aprendizagem da cidadania - Os tempos de juventude de uma republicana singular: Cristina Torres dos Santos (1891-1921). Revista de escritoras ibéricas, n. 2, p. 91-119, 2014. 
SÓNIA COELHO é professora Auxiliar do Departamento de Letras, Artes e Comunicação da Universidade de Trás-os-Montes e Alto Douro, Portugal; doutorada em Ciências da Linguagem pela Universidade de Trás-osMontes e Alto Douro.

E-mail: ccoelho@utad.pt

(D) http://orcid.org/0000-0002-8611-5209

SUSANA FONTES é professora Auxiliar do Departamento de Letras, Artes e Comunicação da Universidade de Trás-os-Montes e Alto Douro, Portugal; doutorada em Linguística Portuguesa pela Universidade de Trás-osMontes e Alto Douro.

E-mail: sfontes@utad.pt

(10) http://orcid.org/0000-0003-4414-9248

Recebido em: 17 de outubro de 2018

Aprovado em: 27 de maio de 2019

Revista História da Educação - RHE

Associação Sul-Rio-Grandense de Pesquisadores em História da Educação - Asphe

Artigo de acesso aberto distribuído nos termos de licença Creative Commons. 